\title{
The Educational Logistic Potential and Supply Chain Link to Agro-Tourism Through Learning the Lifestyle Amphoe Lansaka, Nakorn Sri Thammarat
}

\author{
Tiranan.W, Krittika.J, Nuchakorn.K
}

\begin{abstract}
The purposes of this study were to examine the readiness and accordance of potential, the demand of logistics potential and agro-tourism supply chain in Lan Saka district, Nakhon Si Thammarat province. Questionnaires were distributed to 400 tourists and an interview was conducted with five interviewees from the government/private agencies and entrepreneurs. Analysis of the results revealed that the highest satisfaction was found in three aspects including the community way of life $(\bar{X}=4.29$, S.D. $=0.55)$, the personnel $(\bar{X}=4.50$, S.D. $=0.34)$, and the tourist attractions $(\bar{X}=4.45$, S.D. $=0.54)$, respectively. Respondents highly agreed on two aspects: the physical flow $(\bar{X}=3.82$, S.D. $=0.62$ ( and the information flow ( $\bar{X}=3.94, S . D .=0.56)$, respectively. In tourists' points of view, there should be an improvement on the physical flow and the information flow by emphasizing the location access, providing adequate parking space and travel facilities such as public transport, buses for servicing tourists, signs or symbols, road signs, and viewpoint signs/danger point signs should be provided for convenience in tourist destination access. In view of government/private agencies and entrepreneurs, there should be an emphasis on the physical flow and the tourist destination service, especially transportation services in tourist areas such as enough parking space and network construction linking to nearby location for increasing the opportunities in income distribution and for building sustainable community careers.
\end{abstract}

Keywords: Readiness, Potential, Logistics and Supply Chain, Agro-tourism.

\section{INTRODUCTION}

Lives style of Thai people have long been associated with agriculture because Thailand is an agricultural country with a perfect natural environment, a variety of natural environment, agricultural practices, and local wisdom that are integrated into the agricultural production process. The community way of life was blended in with the beautiful local culture differing in each region of the race; a local identity was inherited from Thai predecessors then.

Revised Manuscript Received on June 22, 2019.

Tiranan.W, Department of Information Systems, Faculty of Management Technology, Rajamangala University of Technology Srivijaya, Nakhon Si Thammarat, Thailand 80110.

Krittika.J, Department of Information Systems, Faculty of Management Technology, Rajamangala University of Technology Srivijaya, Nakhon Si Thammarat, Thailand 80110.

Nuchakorn.K, Department of Information Systems, Faculty of Management Technology, Rajamangala University of Technology Srivijaya, Nakhon Si Thammarat, Thailand 80110.
Agro-tourism has attracted more tourists nowadays as it creates the income for local people in southern Thailand as well as enhances their well-beings due to the potential of agriculture and tourism. The agro-tourism is popular with a large number of tourists since.

There are various agro-tourism destinations such as rafting along the canal or river to experience the nature, community way of life, fishing, vegetable cultivation, gardening, and homestay. Its aim is to develop agricultural areas, natural resources, arts and culture, and traditional ways of life in order to attract tourists to visit agricultural fields so that they have the opportunity to learn the community way of life, the agricultural way, and the production process. To generate the income for local people, agro-tourism must have something that attracts tourists to visit and feel satisfied during their travel for repeated visits. These attractions comprise various tourist destinations and activities which arouse their desire to travel, such as garden events, fruit tastes, local food festivals, excellent service and accommodation availability, of which most of these are already known and have been improved over time. There are largely unrelated to tourist locations, but the logistics and supply chain management is the management of steps in offering continuous chain service which is effective in terms of time, cost, and satisfaction. Tourist destinations require good planning, control, and management as an increase in the number of tourists will affect tourist attractions so good management should take the area capacity into consideration. There is a need for integrated cooperation between the government/private agencies, entrepreneurs and local communities.

As mentioned above, the present study is to seek, and explore the logistics and supply chain potential readiness toward agro-tourism in Lan Saka district, Nakhon Si Thammarat province. Results of the investigation will be used for developing tourism and increasing the competitive capacity of tourism management to create sustainability for the local community.

\section{LITERATURE REVIEW}

(Sirarungrotkanok, P. 2016).This research aimed to study the behavior and satisfaction of Thai tourists toward the tourism logistics management: case study of Amphawa floating Market, 
Samutsongkam Province; to be compare the behavior and satisfaction of Thai tourists toward the tourism logistics management in any impact on demographic differences of Amphawa floating Market, Samutsongkam Province, and to guide for developing on tourism logistics management. 73 samples of Thai tourists were selected by using the questionnaire. Collected the data and then analyzed, using descriptive statistics (frequency, percentage and mean) and inference statistics (t-test and One-Way Analysis of Variance)

The study found that most of tourists were moderately satisfied to very satisfied toward the overall tourism logistics management of Amphawa floating Market, Samutsongkam Province. As the physical facilities, the receiving information, the providing services, the safety of persons and property, and the expenses were moderately satisfied. After that, analyzed the differences between tourists from demographics (gender, age, income, and birthplace), there are statistically significant difference. In terms of the opinion that toward the developing and adjusting on tourism logistics management, should integrate with all of department to fulfill the tourist needs, and should provide the ICT Management to support others system. At last, the cooperation between nearly tourist attractions and local peoples were the best way to be sustainable tourism. [1]

(Phohirun,W. 2014).The purpose of this research study was to investigate the community circumstance of Muban Rongkha Moo 10 of Nuenthai Sub-district, Nahkonthai District, Phisanulok Provice about its potentials and approaches on managing the agricultural tourism business in the community. The mix approached method; i.e. filed survey, observation and in-depth interview for the quantitative, were applied for collecting data. As the key informants, the selected 120 villagers as the purposive sampling were interviewed relating to the community's research management and community development needs and readiness. Besides, the research questionnaires were collected from 392 tourists, who had been travelling to Muban Rongkha.

The results were translated into the Muban Rongkha community agricultural tourism development approach. The suggested areas of development were marketing and network. By process of creating the product differentiation, developing unique packaging, expanding distribution channels and utilizing internet for public relation; creating activity programs for tourists by exploiting the community coordination, cooperation, participation and networking on such agricultural tourism management for sustainability; basic infrastructure development including the tourism data base; training programs for tourism service providers; Hmong culture and heritage preservation; issuing and informing the community's rules and regulations to tourists. [2]

(Rohitratana et al., 2013(.The Study of logistics and Supply Chain System to Strengthen the Capability of Tourism Industry in Thailand. The aim of this research is to find out the approach for improving the effectiveness of tourism management in Thailand and supporting continued growth of the tourism industry under the ASEAN competitive conditions. The analytical framework of the literature review technique is used in analyzing data gathered from the results of them. There are significant gaps noticed in tourism policies such as the lack of explicit and harmonious action plans on tourism development which should also respond to the ASEAN's plan, and the lack of productive human resources and narrative attractions. Consequently, Thailand has been ranked behind in many criteria of ASEAN Tourism Competitiveness, especially in technology infrastructure. For example, the study found that there are many information system problems in the tourism industry such as travel delay; information inaccuracy and exchange restriction in tourism activities, and majority of the entrepreneurs in tourism industry are reluctantly employ information technology to develop their services.

The researchers suggest that the model and data base for entrepreneurs in tourism industry should be categorized according to their characteristics. While, the tourism logistics should focus on physical development such as the common facilities, the public signage in universal format, the cleanliness and safety standards of vehicles, the availability of service personnel, and the reliability of punctuality of the services. [3]

(Intojunyong et al., 2013(. The Study of Supply Chain and Data Model of Tourism Industry in Thailand. The researchers collected data by conducting focus groups with the six relevance stakeholders from 3 of the most popular provinces for tourist; Bangkok, Chiengmai and Suratthani (Samui Island). The six stakeholder groups are consists of 1) Hotel and accommodation, 2) Travel agents, 3) Tourism government agents, 4) Recreational activities companies, 5) Food and restaurant and 6) Transportation companies. In addition, the researchers also conduct in-depth interview with business owners and executives from each stakeholders as well. The researchers concluded that there are only 2 groups within the tourism supply chain that extensively share relevance information with one another. These two groups are Hotel accommodation and travel agents. In addition, the lack of effective collaboration between other stakeholders within the value chain can be contribute from 1) Asymmetric information amongst the 6 stakeholders, 2) the complicated context and cultural complexity and 3) the rapid changes of the information technology that contribute to the information exchanges and collaboration amongst all stakeholders. The researchers also analyzed and develop Thai tourism information exchange model by accumulating all stakeholders and their needs of information within the tourism supply chain. [4]

\section{METHODOLOGY}

\section{Research Design}

A mixed research design employing both quantitative and qualitative methods were used in the study to investigate the logistics and supply chain potential readiness toward agrotourism in Lan Saka district, Nakhon $\mathrm{Si}$ Thammarat province. 


\section{Population and Sample Research}

The samples used in the study were divided into three groups including 400 tourists, 2 interviewees from the government/private agencies and 3 interviewees from entrepreneurs. For the first group, 400 sets of questionnaires using accidental sampling were utilized to collect the data from tourists. Regarding the second and third groups, interviews employing purposive sampling were carried out with interviewees from these two groups.

\section{Research Tool}

A quantitative research design, an accidental sampling technique was used for the study. A set of questionnaire consisting of three parts was administered to 400 tourists.

Part 1 contains tourists' general information.

Part 2 is made up of items concerning logistics and supply chain potential toward agro-tourism.

Part 3 is composed of open-ended questions obtaining information on ways in planning the development of logistics and supply chain potential for agro-tourism.

For the qualitative research, an in-depth interview using purposive sampling was carried out with interviewees from the government/private agencies and entrepreneurs to gather the data concerning agro-tourism as follows:

1. A structured interview was used with interviewees from the government/private agencies and entrepreneurs to obtain in-depth qualitative data regarding the development of logistics and supply chain potential for agro-tourism.

2. A participatory observation method was performed by taking part in various activities such as talks, exchanges and site visits to obtain more accurate information.

\section{Data Collection Methods}

The research was conducted to collect the data using two steps as follows:

1. The secondary data were used to collect the data from documents, textbooks, articles, agro-tourism books, Tourism Authority of Thailand (TAT) websites, and papers relating to agro-tourism, logistics, and supply chain.

2. The primary data using accident sampling were done by distributing 400 sets of questionnaire to visitors in the agrotourism. In-depth interviews employing purposive sampling were done with interviewees from the government/private agencies and entrepreneurs in the agro-tourism area.

\section{Methods and Data Analysis Tools}

In-depth interviews using a purposive sampling method with the government/private agencies and entrepreneurs constituted the qualitative data for the study, whereas the survey employing an accidental sampling method provided the quantitative data on tourists' views and perceptions of agro-tourism destinations. To obtain the actual and reliable information, respondents filled out the questionnaires by themselves and they were asked whether there was some grievance during responding the questionnaires. Those who could not read clearly were read out loud by the researchers, and information obtained was filled out actually. All responses were checked for correctness to get the complete information before performing the data analysis.

Descriptive statistics was used in the study and the data which were expressed as percentage, means, and standard deviations were analyzed by using SPSS.

\section{RESULTS AND DISCUSSION}

\section{Results Analysis Derived from the Questionnaire}

Most respondents $(61.50 \%)$ were female between 31-40 years of age. Most of them had the education level of bachelor's degree $(35.50 \%)$ and were self-employed $(37.75 \%)$. The average income per month was between 10,001-20,000 baht, accounting for $41.50 \%$. They visited this agro-tourism location once, making up $66.50 \%$. The period spent each time was 2 days and 1 night (41.75\%). They received information about agro-tourism from friends and relatives $(52 \%)$, and the vehicles used in travelling were private cars $(61 \%)$. Expenses spent each time for the journey were below 5,000 baht $(46 \%)$. The aim of their trip was relaxation (66.25\%), and recreational activities done in this tourist location were to explore the community way of life, culture, and tradition $(12.80 \%)$. The reason for travelling as a family constitutes $58.50 \%$, and tourists wanted to travel to this tourist destination to see the nature, accounting for $97 \%$. Table 1 shows means, standard deviations, and tourists' opinions toward logistics potential and supply chain linking agro-tourism to learning the community way of life in Lan Saka district, Nakhon Si Thammarat province.

Table.1 Means, standard deviation, and tourists option

\begin{tabular}{lccc}
\hline $\begin{array}{l}\text { Agro-tourism Logistics } \\
\text { Potential and Supply } \\
\text { Chain }\end{array}$ & $\overline{\mathrm{X}}$ & S.D. & $\begin{array}{c}\text { Level of } \\
\text { Opinion }\end{array}$ \\
\hline $\begin{array}{l}\text {.1Information flow } \\
\text {.2Physical flow }\end{array}$ & 3.94 & 0.56 & High \\
.3Financial flow & 3.82 & 0.62 & High \\
.4Tourist destination & 4.35 & 0.54 & Highest \\
$\begin{array}{l}\text { service } \\
\text {.5Tourist attractions }\end{array}$ & 4.43 & 0.63 & Highest \\
.6Community way of life & 4.53 & 0.54 & Highest \\
.7Venue & 4.30 & 0.48 & Highest \\
.8Personnel & 4.50 & 0.34 & Highest \\
\hline \multicolumn{1}{c}{ Total } & $\mathbf{4 . 2 9}$ & $\mathbf{0 . 5 5}$ & Highest \\
\hline
\end{tabular}

As displayed in Table 1, the data obtained from 400 sets of questionnaire revealed that logistics potential readiness and agro-tourism supply chain were found at the highest level $(\bar{X}=4.29$, S.D. $=0.55)$. Considering each aspect, the highest satisfaction was found in the community way of life ( $\bar{X}=4.53$, S.D. $=0.68)$, followed by the personnel $(\bar{X}=4.50$, S.D. $=0.34)$ and the physical flow $(\bar{X}=3.82$, S.D. $=0.62)$.

The information flow was perceived at the high level ( $\bar{X}$ $=3.94$, S.D. $=0.56$ ). When considering each item, it was found that "public relations information in the province, by tell, Tourism Promotion Activities" was the highest level ( $\bar{X}=4.54$, S.D. $=0.56$ ) Secondly was "the information on the internet of agricultural tourism in the province" $(\bar{X}=4.46$, S.D. $=0.59)$. The lowest was "television / radio / newspaper information of tourist destinations or provincial tourism" ( $\bar{X}=3.36$, S.D. $=0.54)$.

Physical flow is the most important. $(\bar{X}=3.82$, S.D. $=0.62$ ) When considering each item, it is found that "the accessibility of the route to 
the tourist attraction, utilization of vehicle access to tourist sites" was the highest level of feedback. $(\bar{X}=4.55$, S.D. $=0.64)$ Secondly, was "safety during travel to tourist destinations". $(\bar{X}=3.98$, S.D. $=0.72)$, and the least was "access to tourist attractions with adequate parking space". ( $\bar{X}=3.31$, S.D. $=0.52$ ).

The overall financial flow is most important. $(\bar{X}=4.35$, S.D. $=0.54)$. When considering each item, "the prices of food and beverages, community products that are appropriate to the prices and services received" were the highest. ( $\bar{X}=4.43$, S.D. =0.51)Secondly, was "the source of the product, gift products are available at reasonable prices". $(\bar{X}=4.39$, S.D. $=0.63$ ) and the least was "the convenience of the payment system to buy goods and services in agricultural tourism" the highest level of opinion. ( $\bar{X}=4.23$, S.D. $=0.55$ ).

The tourism service is overall the most important. ( $\bar{X}=4.43$, S.D. $=0.63$ ). When considering each item, "the agricultural tourism is ready for tourists" was the highest level. ( $\bar{X}$ $=4.53$, S.D. $=0.54$ ) Secondly, "the tourist attractions and the facilities that are available to provide sufficient tourist services". $(\bar{X}=4.45$, S.D. $=0.56)$ a $n \mathrm{~d}$ the least was " the restaurant, the drink in the tourist site is clean, hygienic ready to serve". $(\bar{X}=3.35$, S.D. $=0.66)$.

The overall attraction is the most important $(\bar{X}=4.45$, S.D. = 0.54). When considering each item, "traveling with local life / local wisdom has the interest to travel; the opinions were at the highest level". $(\bar{X}=4.68$, S.D. $=0.45$ ) Secondly was "the environment and atmosphere of tourist attraction facilitates agricultural tourism attract tourists" ( $\bar{X}=4.60$, S.D. $=0.53$ ), and the least was "the attractiveness of the building, which was not built to be the highlight of the attraction". ( $\bar{X}=3.95$, S.D. $=0.53$ ).

Tourism is the most important way of community. $(\bar{X}=4.53$, S.D. $=0.68)$. When considering each item, it was found that "the nature of tourist attraction facilitates agricultural tourism, the community with unique identity" was the highest level of opinion. $(\bar{X}=4.61$, S.D. $=0.58)$ Secondly was "tourists learn the local culture and traditions in the agricultural tourism". ( $\bar{X}=4.58$, S.D. $=0.77)$, and the least is "Promotion of agricultural products in the community" $\overline{\mathrm{X}}=4.47$, S.D. $=0.86$ ).

The place of overall importance is the most important ( $\bar{X}$ $=4.30$, S.D. = 0.49). When considering each item, it is found that "basic utilities have electricity, water, drinking water, public telephone and toilets that are suitable and suitable for agricultural tourism in the community" were at the highest level. ( $\bar{X}=4.63$, S.D. $=0.43$ )Secondly was "enough food and beverage outlets in the tourist area". ( $\bar{X}$ $=4.46$, S.D. $=0.43$ ), and the least was "Traveling facilities include signposts, maps, tourist attractions, to places such as scenic spots, water spots, activity spots $(\bar{X}=4.05$, S.D. $=0.56)$.

Personnel as a whole have the highest priority $(\bar{X}=4.50$, S.D. =0.34). When considering each item, "the staff of the tourist site is courteous and friendly" was the highest level ( $\bar{X}=4.66$, S.D. $=0.39$ ), secondly was "the staff of the tourist care, eager to serve". ( $\bar{X}=4.57$, S.D. $=0.38)$, and the least was "the staff of the tourist service to provide fast" ( $\bar{X}$ $=4.34$, S.D. $=0.45$ ).

A total of 400 questionnaires were collected from tourists and from interviews with government / private agencies and 5 entrepreneurs. From the questionnaire, the visitors had the highest level of opinion in three aspects: tourists. First priority is Community Tourism $(\bar{X}=4.29$, S.D. $=0.55)$, Personnel ( $\bar{X}=4.50$, S.D. $=0.34)$ and attractiveness. $(\bar{X}$ $=4.45$, S.D. $=0.54)$ respectively. There were two levels of opinion: physical flow. ( $\bar{X}=3.82$, S.D. $=0.62)$ and the flow of information. $(\bar{X}=3.94$, S.D. $=0.56)$ respectively. The need for improvement in view of tourists were the physical flow and the flow of information with emphasis on terms of access to the attractions, there are parking spots that are not enough to meet the needs. Transportation to and from public transport is available and banners or symbols, Signpost Including the point of view / danger signs to facilitate access to tourist attractions and in the view of the public / private sector and the operator was the physical flow and tourism services, sufficiency car park. It also creates a network linking tourism to nearby attractions to increase revenue opportunities make a career for a sustainable community.

\section{ACKNOWLEDGMENT}

Research on the availability of logistics and supply chain agri-tourism in Lansaka, Nakhon $\mathrm{Si}$ Thammarat was accomplished with the support of the annual budget of 2560 from Rajamangala University of Technology Srivijaya. Nakhon Si Thammarat CampusThe researcher highly appreciated and appreciated the tourists. State / Private Sector And entrepreneurs in the tourist district of KamLone, Lan Saka District, Nakhon Si Thammarat. Until the research was completed, researcher very grateful for the opportunity. Thank you. all faculty and staff, the support is very good over the past period. Thank you for your support and encouragement in all aspects of your parents, family members, students, counselors to provide advice on all aspects that lead to the completion of this study. Finally, the researcher hopes that the results of this study will be more or less useful to the general audience. If there are any defects, the researcher are welcome to accept and apologize here.

\section{REFERENCES}

1. Sirarungrotkanok, P., (2016). The Behavior and Satisfaction of Thai Tourists Toward the Tourism Logistics Management Case Study: Amphawa Floating Market, Samutsongkarm Province. Master of Science.Burapa University.

2. Phohirun,W.,(2014). The Study and Support the Community Potentiality about Agricultural Tourism Management for SelfDependence of Muban Rongkha Community, Nakhonthai District,Phitsanulok Provice. Pibulsongkram rajabhat university.

3. Rohitratana, K., Charinsarn, A., Rattanaprichavej, N., Intojunyong, S., Ractham , P., Kaewkitipong, L., Satthumnuwong, N., Laosirihongthong, T., Buhtyoo, T.,(2013). The Study of logistics and Supply Chain System to Strengthen the Capability of Tourism Industry in Thailand. National Research Council of Thailand( NRCT) and The Thailand Research Fund (TRF). 
4. Intojunyong, S., Rohitratana, K., Charinsarn, A., Rattanaprichavej, N.,Ractham , P., Kaewkitipong, L., Satthumnuwong, N., Laosirihongthong, T., Buhtyoo, T.,(2013). The Study of Supply Chain and Data Model of Tourism Industry in Thailand. National Research Council of Thailand( NRCT) and The Thailand Research Fund (TRF).

5. Suralai, W., (2013).Guidelines for Sustainable on Agro-Tourism Destinations Development : A Case Study of Wang Nam Keaw District,Nakorn Ratchasima Province. Master of Business Administration Independent Study in Tourism Management, Faculty of Management Science, Khon Kaen University.

6. Promprasit, N., (2013). The way in marketing development of agrotourism at Koh Yor, Muang District, Songkhla Provice. Master of Business Administration. Songkhla Rajabhat University. 